\title{
The Future for Dementia Research: a Perspective from the Journal of Molecular Neuroscience
}

\author{
Illana Gozes ${ }^{1}$
}

Published online: 19 September 2016

(C) Springer Science+Business Media New York 2016

The present issue of the Journal of Molecular Neuroscience, a most welcomed initiative of the guest editors, George Fink, Peng Lei, and Ashley Ian Bush, provides an excellent focus on various aspects of dementia, summarizing important findings and facing the future. A question frequently asked by lay audience is whether dementia equals Alzheimer's disease. Indeed, Alzheimer's disease is the most prevalent dementia, but as exemplified in the current issue, other pathologies also lead to dementia.

From the point of view of Alzheimer's disease and dementia, the Journal of Molecular Neuroscience provides a stage for global special issues (e.g., Gozes 2001; Sisodia and Tanzi 2001; Fillit et al. 2002; Refolo and Fillit 2004b), as well as for issues focusing on specific molecular targets, like tau (Fillit and Refolo 2002; Gozes 2002), or on the major Alzheimer's risk gene, apolipoprotein E (Gozes 2004; Refolo and Fillit 2004a). Other important aspects of dementia are covered in special issues as well, for example, a focus on frontotemporal dementia (Ghetti 2011; Gozes 2011). In general, neurodegeneration was recently covered in a meeting report (Gozes et al. 2015) as well as in an issue dealing with muscular atrophy (Pennuto and Gozes 2016).

With the seminal findings of the Australian, Colin Masters, the first to complete the sequence of beta-amyloid, a main therapeutic target against Alzheimer's disease (Masters et al. 1985), and the first to clone the amyloid protein precursor

\section{Illana Gozes}

igozes@post.tau.ac.il

1 The Lily and Avraham Gildor Chair for the Investigation of Growth Factors, Elton Laboratory for Neuroendocrinology, Department of Human Molecular Genetics and Biochemistry, Sackler Faculty of Medicine, Adams Super Center for Brain Studies and Sagol School of Neuroscience, Tel Aviv University, 69978 Tel Aviv, Israel gene (Kang et al. 1987), a focus on dementia research emanating from Australia, is of great importance, paving the path to major future breakthroughs. Thus, this current issue is timely and focused.

Interestingly, a recent article published in the Nature (August 31, 2016) (Sevigny et al. 2016) addresses immunotherapy as a preventative disease modifying passive vaccination against Alzheimer's disease. This article addresses again the amyloid hypothesis as a driver of Alzheimer's disease. Indeed, the pathology of amyloid plaques is specific to Alzheimer's disease, with the familial form of the disease caused by mutations either in the amyloid precursor protein or in presenilin. However, presenilin presents the most mutations in familial Alzheimer's disease and may be associated with pathways other than the amyloid pathway (De Strooper 2007). Furthermore, healthy individuals present amyloid plagues in their brains (e.g., (Kawas et al. 2013; Malishkevich et al. 2015)). Previous clinical trials addressing Alzheimer's vaccination at the level of the amyloid peptide mostly failed, albeit showing varying degrees of clearance of the amyloid plague burden (e.g., (Salloway et al. 2014)). The recent study differs from previous evaluations in that the antibodies are now targeting aggregated amyloid and probably recognizing soluble, toxic, aggregated amyloid in the patient brain. A further difference is that the current study is targeting a prodromal or very mildly affected population, showing a slowing of clinical decline as measured by the Clinical Dementia Rating-Sum of Boxes and Mini Mental State Examination scores, paralleling amyloid clearance. Indeed, other investigational drugs showed cognitive protection in this population (e.g., (Gozes et al. 2009; Ayton et al. 2013; Morimoto et al. 2013)). The impact of tauopathy, a major hallmark of Alzheimer's disease and other neurodegeneration (Pachima et al. 2016), is not directly addressed in the most recent study. However, an ongoing clinical trial (BIOGEN 
IDEC) may solve the mystery of Alzheimer's related amyloid vaccination in the fight against neurodegeneration and dementia affecting the elderly population. These studies would not have been possible without the pioneering original amyloid discoveries including the cutting-edge articles cited above (Masters et al. 1985).

The current issue of the Journal of Molecular Neuroscience covers many aspects of dementia, as outlined in the "Introduction" section to the issue (Bush et al. 2016), and the more we understand, the better treatment we can give toward Alzheimer's disease and other dementias becoming only memories.

From the desk of the Editor-In-Chief.

\section{References}

Ayton S, Lei P, Bush AI (2013) Metallostasis in Alzheimer's disease. Free Radic Biol Med 62:76-89

Bush AI, Fink G, Lei P (2016) Australia Dementia Research Development Fellowship Program: The Future for Australian Dementia Research. J Mol Neurosci. doi:10.1007/s12031-0160842-4

De Strooper B (2007) Loss-of-function presenilin mutations in Alzheimer disease. Talking point on the role of presenilin mutations in Alzheimer disease. EMBO Rep 8:141-146

Fillit HM, Refolo LM (2002) Tau and Alzheimer's disease: the long road to anti-tangle therapeutics. J Mol Neurosci 19:249-250

Fillit HM, O'Connell AW, Refolo LM (2002) Strategies for drug discovery for cognitive aging and Alzheimer's disease. J Mol Neurosci 19:1-3

Ghetti B (2011) Introduction: from the desk of the guest editor. J Mol Neurosci 45:321

Gozes I (2001) Alzheimer's disease: my point of view. J Mol Neurosci 17:269-270

Gozes I (2002) Tau as a drug target in Alzheimer's disease. J Mol Neurosci 19:337-338

Gozes I (2004) Apolipoprotein E knockout mice as a model of behavioral dysfunction. J Mol Neurosci 23:149-150

Gozes I (2011) From the desk of the editor-in-chief journal of molecular neuroscience: frontotemporal dementias with the face to future research and development. J Mol Neurosci 45:323

Gozes I, Baas PW, Richter-Landsberg C (2015) International meeting molecular neurodegeneration: news and views in molecular neuroscience in health and disease. Delmenhorst, Germany, July 20-22, 2015. J Mol Neurosci 57:153-159
Gozes I, Stewart A, Morimoto B, Fox A, Sutherland K, Schmechel D (2009) Addressing Alzheimer's disease tangles: from NAP to AL108. Curr Alzheimer Res 6:455-460

Kang J, Lemaire HG, Unterbeck A, Salbaum JM, Masters CL, Grzeschik KH, Multhaup G, Beyreuther K, Muller-Hill B (1987) The precursor of Alzheimer's disease amyloid A4 protein resembles a cell-surface receptor. Nature 325:733-736

Kawas CH, Greenia DE, Bullain SS, Clark CM, Pontecorvo MJ, Joshi AD, Corrada MM (2013) Amyloid imaging and cognitive decline in nondemented oldest-old: the 90+ study. Alzheimers Dement 9:199_ 203

Malishkevich A, Marshall GA, Schultz AP, Sperling RA, Aharon-Peretz J, Gozes I (2015) Blood-borne activity-dependent neuroprotective protein $(\mathrm{ADNP})$ is correlated with premorbid intelligence, clinical stage, and Alzheimer's disease biomarkers. J Alzheimers Dis 50: 249-260

Masters CL, Simms G, Weinman NA, Multhaup G, McDonald BL, Beyreuther K (1985) Amyloid plaque core protein in Alzheimer disease and down syndrome. Proc Natl Acad Sci U S A 82:42454249

Morimoto BH, Schmechel D, Hirman J, Blackwell A, Keith J, Gold M (2013) A double-blind, placebo-controlled, ascending-dose, randomized study to evaluate the safety, tolerability and effects on cognition of AL-108 after 12 weeks of intranasal administration in subjects with mild cognitive impairment. Dement Geriatr Cogn Disord 35:325-336

Pachima YI, Zhou LY, Lei P, Gozes I (2016) Microtubule-tau interaction as a therapeutic target for Alzheimer's disease. J Mol Neurosci 58: $145-152$

Pennuto M, Gozes I (2016) Introduction to the special issue on spinal and bulbar muscular atrophy. J Mol Neurosci 58:313-316

Refolo LM, Fillit HM (2004a) Apolipoprotein E4 as a target for developing new therapeutics for Alzheimer's disease. J Mol Neurosci 23: $151-155$

Refolo LM, Fillit HM (2004b) Drug discovery for Alzheimer's disease: the end of the beginning. J Mol Neurosci 24:1-8

Salloway S, Sperling R, Brashear HR (2014) Phase 3 trials of solanezumab and bapineuzumab for Alzheimer's disease. N Engl J Med 370:1460

Sevigny J, Chiao P, Bussiere T, Weinreb PH, Williams L, Maier M, Dunstan R, Salloway S, Chen T, Ling Y, O'Gorman J, Qian F, Arastu M, Li M, Chollate S, Brennan MS, Quintero-Monzon O, Scannevin RH, Arnold HM, Engber T, Rhodes K, Ferrero J, Hang Y, Mikulskis A, Grimm J, Hock C, Nitsch RM, Sandrock A (2016) The antibody aducanumab reduces Abeta plaques in Alzheimer's disease. Nature 537:50-56

Sisodia S, Tanzi RE (2001) Guest editor's introduction: Alzheimer's disease clinical, biological, and therapeutic perspectives. J Mol Neurosci 17:1 